\title{
Saline poisoning caused by Laser-Photo-Vaporization XPS-180W: A different irrigation fluid absorption syndrome. Acute pulmonary oedema and hyperchloremic metabolic acidosis without hyponatremia.
}

\begin{abstract}
N. Aracil Escoda, A. Tirado Errazquin, E. Martínez Hurtado, J. Ripollés Melchor, R. Navarro Pérez, A. Abad-Gurumeta. Hospital Universitario Infanta Leonor, Madrid. España.
\end{abstract}

\section{Background:}

Photoselective vaporization of the prostate (PVP) is an endoscopic urological technique using saline $0.9 \%$ as irrigation fluid, preventing the Transurethral Resection Syndrome (TURP). Fluid absorption is frequent, but clinical symptoms are rare and only mild to moderate. We present a case of irrigation fluid absorption syndrome in a PVP, with significant clinical manifestations.

\section{Case Report:}

75-years-old male was scheduled for a Laser PVP. The procedure lasted 35 min. under spinal anaesthesia. Ending the surgery patient becomes breathless, abdomen was distended and he has subconjubctival oedema. Abdominal ultrasound found free fluid and he was reoperated objectifying a capsular perforation. During the procedure he developed acute pulmonary oedema. Blood test results can be seen in the table. Furosemide $40 \mathrm{mgr}$. was prescribed to achieve negative fluid balance, with good response allowing extubation after 7

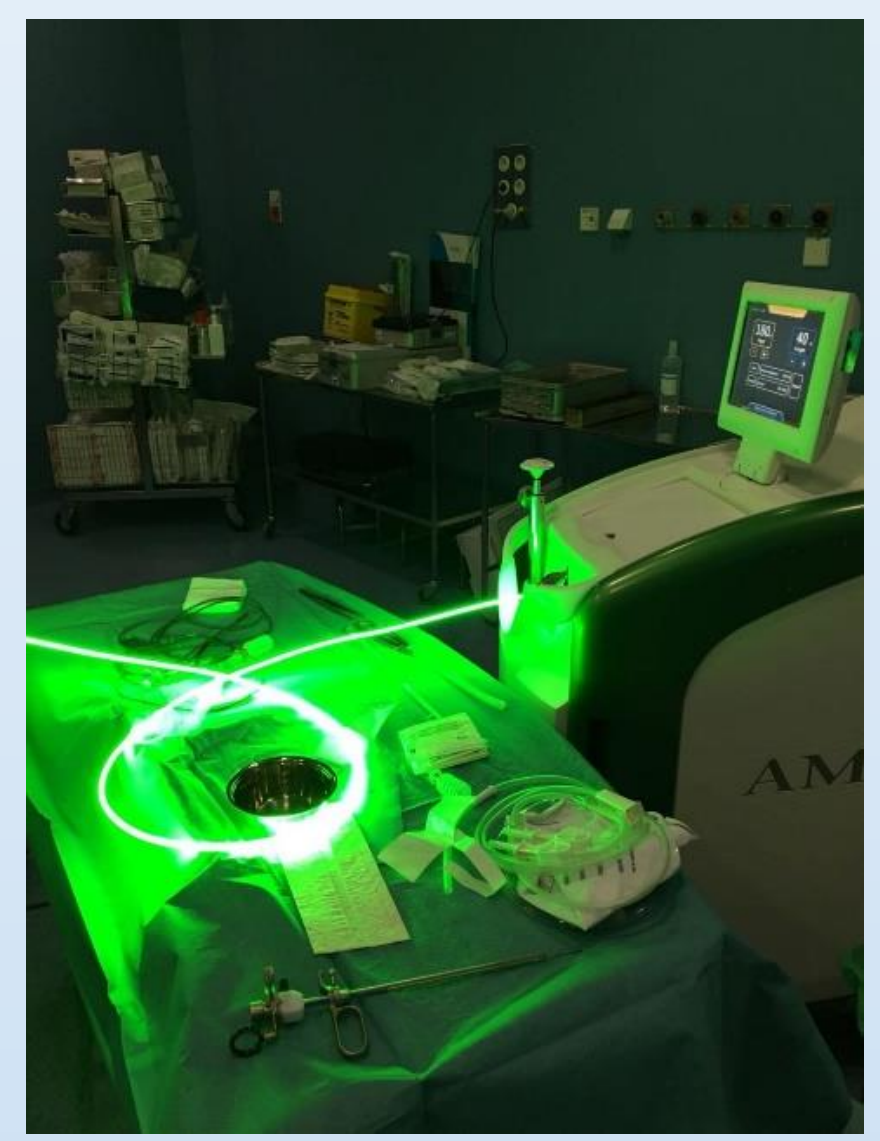
hours, and $-2240 \mathrm{ml}$ of balance. He left the recovery room next day.

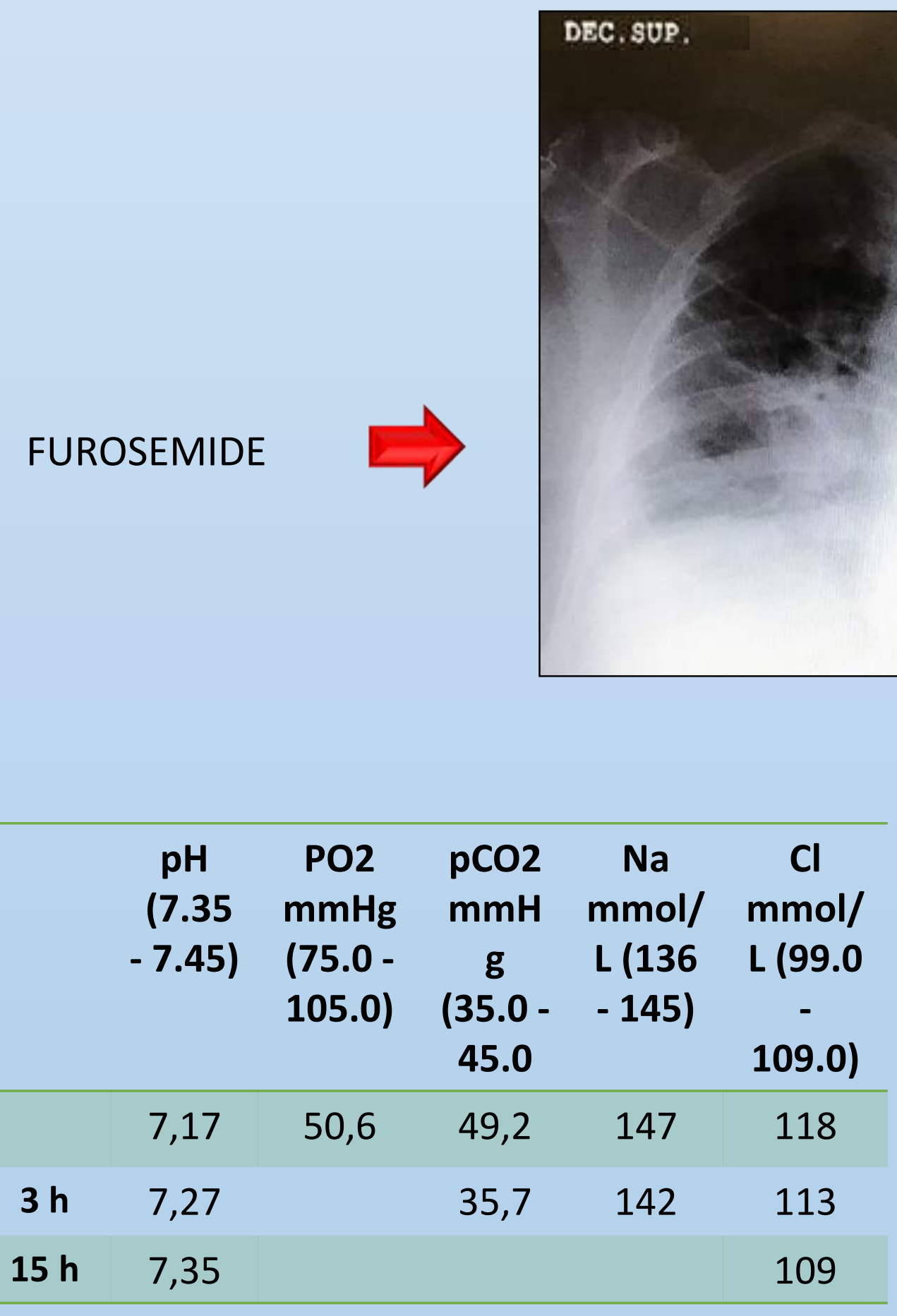

Learning points:

Laser-photo-vaporization of the prostate is not a risk-free technique; reabsorption of the irrigation isotonic fluid (saline solution $0.9)$ can lead the patient to a dangerous situation. Fortunately serious complications are uncommon.

1. Contemporary surgical treatment of benign prostatic hyperplasia.Nunes RLV et al. Rev Assoc Med Bras (1992). 2017 Aug;63(8):711-716.

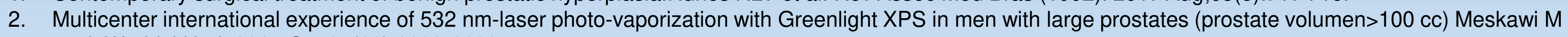
et al. World J Urol. 2017 Oct;35(10):1603-1609.

3. Prospective evaluation of irrigation fluid absorption during pure transurethral bipolar plasma vaporisation of the prostate using expired-breath ethanol measurements. Hermanns T. et al. BJU Int. 2013 Sep;112(5):647-54. 